\title{
A prática do apoio matricial e os seus efeitos na Atenção Primária à Saúde
}

\author{
Meyrielle Belotti ${ }^{\mathrm{a}}$, Maria Cristina Campello Lavrador ${ }^{\mathrm{b}}$ \\ ${ }^{a}$ Departamento de Educação Integrada em Saúde, Universidade Federal do Espírito Santo - UFES, \\ Vitória, ES, Brasil. \\ ${ }^{b}$ Departamento de Psicologia, Universidade Federal do Espírito Santo - UFES, Vitória, ES, Brasil.
}

\begin{abstract}
Resumo: Introdução: Este trabalho insere-se no contexto das discussões sobre a saúde mental na Atenção Primária à Saúde. Trata-se de um relato de experiência da prática do Apoio Matricial em uma Unidade Saúde da Família, situada em um município da Grande Vitória, ES, Brasil. Objetivo: Buscou-se identificar os efeitos que os encontros de matriciamento provocaram no território de adstringência das equipes da Estratégia Saúde da Família acompanhadas. Método: Para a realização dos encontros de matriciamento, foi utilizado o Método de Roda. Resultados: Os resultados apontam que a prática do Apoio Matricial favoreceu a ampliação das estratégias de cuidados em saúde mental na Atenção Primária à Saúde; a corresponsabilidade no cuidado; a escuta qualificada; o aumento da resolutividade neste nível de atenção; e a diminuição dos encaminhamentos sem critérios. Conclusão: Neste sentido, o Apoio Matricial foi uma ferramenta capaz de promover uma interlocução entre os serviços de saúde mental e a Atenção Primária à Saúde. Neste caminho, o Projeto Terapêutico Singular (PTS) configurou-se como um grande aliado, proporcionando a construção de decisões e tarefas definidas de modo compartilhado, favorecendo o envolvimento e a responsabilização de todos no cuidado do sujeito com sofrimento psíquico.
\end{abstract}

Palavras-chave: Saúde Mental, Saúde da Família, Atenção à Saúde.

\section{The practice of matrix support and its effects on primary health care}

\begin{abstract}
Introdução: This work is part of the context of discussions on mental health in primary health care. It is an experience report of Matrix Support practice in a Family Health Unit located in a city of Grande Vitória, ES, Brazil. Objective: We sought to identify the effects that the matrix meetings had in the astringency territory of the Family Health Strategy teams followed up. Method: The matrix meetings were performed using the Circle approach. Results: The results show that the practice of the Matrix Support favored the expansion of care strategies for mental health in primary health care; co-responsibility in the care; qualified hearing; increased resolution in this level of attention; and decrease of referrals without criteria. Conclusion: In this regard, the Support Matrix was a tool able to promote a dialogue between mental health services and primary health care. Thus, the Singular Therapeutic Project became a great ally, providing the construction of decisions and shared tasks, allowing the involvement and accountability of all caring for the person with psychiatric suffering.
\end{abstract}

Keywords: Mental Health, Family Health, Health Care. 


\section{Introdução}

Atualmente estamos diante de um amplo processo de transformação no campo da saúde mental, que tem se esforçado para desconstruir a "lógica manicomial", bem como as relaçóes de tutela estabelecida com o louco. Para tanto, observamos uma valorização das práticas de base territoriais com o envolvimento de diversos atores sociais articulados em uma rede de cuidados. Neste cenário, a Atenção Primária à Saúde (APS) tem se mostrado como um lugar privilegiado para a construção de uma nova lógica de acolher a loucura, por seus princípios estarem pautados na integralidade da atenção, no acolhimento, no compromisso com a comunidade, no estabelecimento de vínculo e na articulação de rede (BRASIL, 2012).

De acordo com Silva (2010), a inclusão da saúde mental na APS deverá ser realizada através da criação de estratégias de cuidado capazes de reconhecer as diferenças e as limitaçóes da pessoa com sofrimento psíquico, favorecendo, assim, a clínica ampliada.

A partir dessa proposta, busca-se propor estratégias singulares de atenção e cuidado, resgatando vínculos, comprometendo as equipes de saúde, potencializando o cuidado familiar e o acompanhamento ao longo do tempo (SILVA, 2010, p. 17).

Para Merhy (2006, p. 199), a APS deve ser entendida como lugar estratégico de intervenção para a redefinição das práticas, visando a uma mudança de direção de um sistema "hospitalocêntrico" para um "redebasicocêntrico", [...] "podendo abrir-se, portanto, às mais distintas alternativas de constituição de novos formatos de produçáo das açóes de saúde".

Assim, a inserção da saúde mental na APS é uma estratégia fundamental

[...] para a reorganização da atenção à saúde que se faz urgente em nossa realidade, na medida em que rompe dicotomias tais como saúde/saúde mental, exigindo a produção de práticas dentro do princípio da integralidade (DIMENSTEIN et al., 2005, p. 26).

Neste cenário, o Apoio Matricial (AM) pode ser utilizado como uma ferramenta capaz de promover uma interlocuçáo entre os serviços de saúde mental e a APS, visto que se constituiu em um

[...] arranjo organizacional que viabiliza o suporte técnico em áreas específicas para equipes responsáveis pelo desenvolvimento de ações básicas de saúde [...] (BRASIL, 2005, p. 34).

Sua proposta visa à ampliaçáo da capacidade resolutividade das equipes da APS, bem como a implantaçáo de uma clínica ampliada e a corresponsabilidade do cuidado.

Em outras palavras, o AM em saúde mental se propóe a dar suporte, a discutir, a intervir conjuntamente e a capacitar os profissionais da APS para o cuidado em saúde mental. Trata-se de assegurar retaguarda assistencial e suporte técnico-pedagógico às equipes que prestam atençáo aos problemas de saúde da população (CAMPOS; DOMITT, 2007).

$\mathrm{Na}$ prática, o AM acontece a partir de reunióes, com a presença da equipe da APS e dos profissionais apoiadores, com discussóes a respeito dos casos de saúde mental identificados no território. Em algumas ocasióes específicas poderáo ocorrer intervençóes em conjunto (visitas domiciliares, atendimentos, entre outros) para melhor "resolutividade" do caso. Dessa forma, pretende-se qualificar as equipes da APS para uma atençáo ampliada, bem como para a distinção dos casos que podem ser acolhidos neste nível de atenção das reais situaçóes que necessitam de um cuidado especializado em saúde mental.

Campos e Domitt (2007) ressaltam que na prática do AM está implícita a construção dos Projetos Terapêuticos Singulares (PTS). Os PTS se configuram como uma ferramenta para a construção de práticas inovadoras, que singularizam os processos dos sujeitos e suas necessidades de saúde, apresentando novas perspectivas na produçáo de autonomia, protagonismo e inclusão social (BARROS, 2010). Sendo assim, o PTS é um instrumento que incorpora um olhar de singularidade, envolvendo e responsabilizando, necessariamente, a equipe de saúde e o usuário na condução dos interesses em comum.

De acordo com o Ministério da Saúde (BRASIL, 2006), o PTS nada mais é do que uma nova forma de realizar a discussão de "caso clínico", capaz de proporcionar uma atuação integrada da equipe, incorporando outros aspectos, além do diagnóstico psiquiátrico e da medicação no tratamento dos sujeitos. Portanto, sua elaboração ocorre em espaços de discussôes, em que todos os saberes são importantes e contribuem para ajudar a entender o sujeito com alguma demanda de cuidado em saúde.

Este artigo é fruto de um relato de experiência, sobre a implantaçáo do AM em uma Unidade Saúde da Família (USF), situada em um município da Grande Vitória-ES. Sua proposta consiste em apresentar e discutir os efeitos que os encontros de matriciamento provocaram no território de adstringência da UBS acompanhada.

\section{Método}

Para a condução dos encontros de matriciamento, optou-se pelo Método de Roda, visando possibilitar a construção de espaços coletivos, propícios para a reflexão crítica sobre o cotidiano do serviço e o processo de trabalho. Buscou-se potencializar 
a capacidade de análise desses sujeitos sobre suas práticas de saúde e a operacionalizaçáo da cogestão (CAMPOS; DOMITTI, 2007).

Cabe ressaltar que os encontros de matriciamento tinham como proposta favorecer a interlocução entre a APS e a saúde mental; gerar conhecimento para as equipes da ESF no campo da saúde mental; ampliar o escopo das açóes em saúde mental na APS, e consequentemente promover o aumento do grau de resolutividade dos casos de saúde mental neste nível de atenção. Assim, buscou-se possibilitar aos profissionais a análise reflexiva dos processos de trabalho visando o questionamento de processos cristalizados; ou seja, a intenção não era a realização de grandes mudanças estruturais, mas sim, a criação de novas estratégias de cuidado capazes de romper com a lógica manicomial.

O cenário dessa experiência foi uma USF localizada em um município da Grande Vitória, ES, Brasil. a qual situava-se em um território carente e com características rurais. No que se refere à rede de cuidado em saúde mental do município em questão, essa apresenta uma complexidade própria, pois possui em seu território serviços que são de gestão municipal e outros que são de gestão estadual. Sob gestáo municipal existem três ambulatórios de Saúde Mental que funcionam nas Unidades Básicas de Saúde. Sob gestão estadual, existem dois Centros de Atenção Psicossocial II (CAPS), sete Residências Terapêuticas (RT) e um Hospital Estadual que é referência para toda a Grande Vitória em Urgência e Emergência de Psiquiatria.

Em um primeiro momento, antes do funcionamento das rodas de conversa, foi realizada uma reunião com os profissionais da USF para a apresentação da proposta do AM e a sua metodologia de trabalho. Todos os profissionais da USF foram convidados a participar. Ao total participaram 24 profissionais de saúde, das seguintes categorias: enfermeiros, assistentes sociais, agentes comunitários de saúde e técnicos de enfermagem. Os encontros aconteciam na USF, com uma frequência quinzenal, salvo nas situaçóes emergenciais que eram demandadas pelas equipes da ESF.

As rodas de conversa foram realizadas no período de fevereiro a setembro de 2012. Ao total foram realizados 18 encontros, com a duração de aproximadamente duas horas cada um. Os encontros contavam com a presença dos profissionais das três equipes da ESF e de dois profissionais de saúde mental, técnicos de referência em saúde mental nos territórios de adstringência da USF, e que desenvolviam o papel de apoiadores em saúde mental.

\section{Resultados e Discussão}

Inicialmente, foi possível constatar que as açóes de saúde mental realizadas pelas equipes $\mathrm{da}$ ESF acompanhadas, antes do matriciamento, se restringiam em encaminhamentos aos serviços de saúde mental, sem nenhum tipo de implicação e acolhimento do sujeito com sofrimento psíquico. Diante desse cenário, identificou-se um número excessivo de encaminhados sem critérios aos serviços de saúde mental, ou seja, na sua grande maioria, esses encaminhamentos não apresentavam uma demanda específica que justificasse a necessidade de uma atenção especializada. Tal realidade se fez presente em funçáo da dificuldade dos profissionais de realizarem uma escuta qualificada e pela sensação de impotência vivenciada por estes diante de uma demanda de saúde mental. Aliado a esse quadro, verificou-se a falta de preparo e de capacitaçáo em saúde mental e a presença de estigmas acerca da loucura.

A sensação de impotência, que permeia o cuidado em saúde mental, pode estar atrelada a uma atuação dentro de uma perspectiva do modelo biomédico, que é pautado na doença, na remissão dos sintomas com vistas à cura. No campo da saúde mental, esse modelo de atençáo torna-se inviável. Por essa razáo, entre outras, muitas das expectativas criadas em torno dos usuários com sofrimento psíquico não são alcançadas, causando sofrimento ao trabalhador.

O sentimento de impotência também pode ser justificado pela ausência de conhecimento no campo da saúde mental. Diversos estudos (SILVEIRA; VIEIRA, 2009; JUCA; NUNES; BARRETO, 2009; BRÊDA et al., 2005) evidenciam a existência de um despreparo nas equipes da APS para atuar com os sujeitos em sofrimento psíquico. Queiroz (2010) aponta que o desafio atual do Movimento da Reforma Psiquiátrica consiste em garantir a produção de cuidado na APS. Para tanto, torna-se necessário que: a) as equipes estejam treinadas e qualificadas para as demandas em saúde mental; b) os profissionais estejam preparados para realizar uma escuta qualificada; c) todos os membros da equipe da APS conheçam a forma como se organiza a rede de saúde mental, a fim de garantir a integralidade do cuidado.

No que se refere ao estigma em torno da loucura, identificou-se a existência da concepção de uma correlaçáo da periculosidade com a loucura, na qual alguns profissionais relataram que sentiam medo de serem agredidos pelos sujeitos com sofrimento psíquico e por isso não realizavam nenhum tipo de estratégia de cuidado em saúde mental no território de adstringência. 
Godoy e Bosi (2007, p. 294) ressaltam que a reclusão imposta ao sujeito com sofrimento psíquico favoreceu a construção social do estigma da loucura.

Sobre o louco é exercida uma ação de violência, de múltiplas segregaçóes: da reclusão ao abandono nu e imundo no pátio do manicômio, construindo-se a concepçáo do louco enquanto ser perigoso, nefasto, incapaz, um "não ser", legitimando-se a condição de "não cidadão", "não sujeito".

Para Goffman (1988, p. 15), a redução do sujeito ao seu traço estigmatizado, legitima "[...] vários tipos de discriminação, através das quais efetivamente, e muitas vezes sem pensar, reduzimos suas chances de vida." Os estigmas em torno da loucura, presentes no imaginário social, são concebidos como empecilhos no avanço da concepção de um outro lugar social à loucura.

O lugar social da loucura, a despeito de um certo deslocamento produzido, permanece ainda, de modo geral, aquele de situar-se à margem da sociedade [...] (NUNES; TORRENTE, 2009, p. 104).

Diante deste cenário e visando promover uma aproximação da temática da saúde mental com as equipes da ESF acompanhadas, bem como a sua capacitação neste campo de atuaçáo, os primeiros encontros de matriciamento assumiram um caráter pedagógico. Assim, foram realizadas leituras e discussōes de texto sobre a política de saúde mental no Brasil, bem como, apresentada a rede de cuidado em saúde mental do município em questáo. Através desses encontros, surgiu a proposta para a construçáo de um formulário para ser utilizado durante o acolhimento em saúde mental. O formulário foi elaborado com questôes que contemplavam para além dos aspectos biológicos, aspectos tais como: a constituição familiar e suas relaçôes, o contexto social do usuário, seu cotidiano, desejos e perspectivas de vida.

Paralelamente à construção do formulário de acolhimento, foi realizado um mapeamento dos equipamentos/serviços existentes na comunidade, no intuito de integrá-los como mais um recurso terapêutico dos PTS, não restringindo as suas açôes às questôes clínicas. Além disso, a proposta do mapeamento dos recursos sociais existentes na comunidade tinha como objetivo buscar espaços nos quais os sujeitos com sofrimento psíquico pudessem circular junto a outros, com o intuito de desmistificar a loucura e suas práticas de caráter manicomial e excludente. Neste processo de mapeamento, foram identificados os seguintes recursos territoriais: escola aberta com diversos cursos profissionalizantes e atividades culturais e de lazer; um projeto social que confecciona artesanato com material reciclado; e outro que desenvolvia práticas esportivas. Cabe ressaltar que, além destes recursos territoriais identificados, as açôes do PTS também eram articuladas com a rede de saúde do referido município, sendo esta acionada a partir da demanda apresentada pelo usuário. Assim, tanto os serviços de saúde, em seus diferentes níveis de complexidade (APS, Média Complexidade e Alta Complexidade), quanto os serviços de saúde mental eram contemplados nos PTS de acordo com a necessidade e complexidade do caso discutido.

Depois da conclusão dessa etapa, iniciaram-se as discussões dos casos e a implantação dos PTS, nas situaçóes que apresentavam maior complexidade, ou seja, nos casos severos e persistentes, eleitos pela equipe. A estruturação do PTS foi desenvolvida a partir das seguintes etapas: 1) elaboração do diagnóstico situacional, contemplando os aspectos orgânicos, psíquicos e do contexto do sujeito singular; 2) negociação e planejamento das ações com o usuário e seu(s) cuidador(es), sendo que cada açáo do projeto possuía prazo de realização e responsáveis para a execução; 3) reavaliação para ajuste das açôes. Cabe ressaltar que o usuário e seu(s) cuidador(es) também possuíam responsabilidades na execução do PTS.

Todas as açôes do PTS eram acompanhadas por um profissional que assumia o papel do articulador e potencializador do processo, estabelecendo uma relação de parceria com as redes de apoio. Esse profissional tornava-se referência para a equipe e para o usuário e o(s) cuidador(es) envolvido(s), mantendo o grupo sempre informado sobre o caso e demandando novas discussóes, se preciso fosse, visto que as ações dos projetos eram flexíveis e passíveis de mudanças. A escolha do profissional de referência era realizada levando em consideraçáo a qualidade do vínculo com o usuário.

Algumas dificuldades foram surgindo durante a elaboração e implantaçáo dos PTS, tais como: busca de respostas imediatas e prontas que visavam à cura e que remetiam ao modelo biomédico; criação de vínculo com os usuários e cuidadores envolvidos; respeito às escolhas e ao tempo dos usuários; escuta qualificada comprometida; respeito à singularidade. No entanto, com o passar das discussóes em torno da construção dos PTS, percebeu-se um aprimoramento do olhar sobre o cuidado em saúde mental e essas dificuldades começaram a ser amenizadas.

Ao longo do percurso, foi possível verificar que a prática do AM, promoveu uma mudança na forma 
de lidar com a "loucura", ocasionando alguns efeitos no território acompanhado, tais como: oferta de uma escuta qualificada ao sujeito com sofrimento psíquico; redução dos encaminhamentos sem critérios aos serviços de saúde mental; criação de estratégias de cuidado em saúde mental; e a corresponsabilidade pelo cuidado.

\section{Conclusão}

Este artigo relata a experiência de implantação do AM em saúde mental na Atenção Primária à Saúde. Sua proposta constitui-se em analisar os efeitos produzidos no território de saúde mediante os encontros de matriciamento. Ao longo da realização das rodas de conversa, verifica-se um empoderamento das equipes da ESF em relação à atuação no campo da saúde mental, o que favoreceu: a ampliação das estratégias de cuidados em saúde mental; a corresponsabilidade no cuidado; o aumento do grau de resolutividade dos casos de saúde mental neste nível de atenção; a escuta qualificada; e a diminuição dos encaminhamentos sem critérios. Tal realidade reitera a proposta da IV Conferência de Saúde Mental, que solicita em seu relatório final, o fortalecimento e ampliação das açóes da ESF, reafirmando a estratégia do matriciamento como uma das ferramentas importantes para a inserção dos usuários no nível da APS (BRASIL, 2010).

Não se pode deixar de destacar a importância do PTS durante os encontros de matriciamento. O PTS se mostrou útil para mediar relaçóes e estabelecer um diálogo entre a equipe de saúde, os usuários e os cuidadores, proporcionando a construção de decisóes e tarefas definidas de modo compartilhado, favorecendo o envolvimento e a responsabilizaçâo de todos no cuidado do sujeito com sofrimento psíquico.

Essa experiência também indica a importância do investimento tanto nas açôes do AM para o fortalecimento da saúde mental na APS, quanto para a incorporação efetiva da saúde mental neste nível de atenção, através da produção de conhecimento baseada nas premissas do modelo de atenção psicossocial, contrapondo-se à lógica manicomial.

É importante frisar que uma das limitaçôes desta experiência, deve-se ao fato de o estudo ter sido realizado somente em uma USF, sendo que os resultados encontrados não podem caracterizar os efeitos do AM em todo o município. Ressalta-se ainda, a dificuldade da participação dos médicos nos encontros de matriciamento, visto que a inserção desse profissional poderia enriquecer as discussões e elaboraçóes do PTS.

\section{Referências}

BARROS, J. O. A construção de projetos terapêuticos no campo da saúde mental: apontamento acerca das novas tecnologias de cuidado. 2010. 110 f. Dissertaçáo (Mestrado em Ciências de Reabilitação) - Universidade de São Paulo, São Paulo, 2010.

BRASIL. Ministério da Saúde. Conselho Nacional de Saúde. Relatório Final da IV Conferência Nacional de Saúde Mental - Intersetorial. Brasília: Ministério de Saúde, 2010.

BRASIL. Ministério da Saúde. Política Nacional de Atençâo Primária a Saúde. Brasília: Ministério da Saúde, 2012.

BRASIL. Ministério da Saúde. Secretaria de Atenção à Saúde. Coordenação Geral de Saúde Mental. Reforma psiquiátrica e politica de saúde mental no Brasil. Brasília: Ministério da Saúde, 2005. Documento apresentado à Conferência Regional de Reforma dos Serviços de Saúde Mental: 15 anos depois de Caracas.

BRASIL. Ministério da Saúde. Formação de apoiadores para a política nacional de humanização da gestão e da atenção à saúde. Rio de Janeiro: FIOCRUZ, 2006.

BRÊDA, M. Z. et al. Duas estratégias e desafios comuns: a reabilitação psicossocial e a saúde da família. Revista Latino-Americana Enfermagem, Ribeirão Preto, v. 13, n. 3, p. 450-452, 2005.

CAMPOS, G. W. S.; DOMITT, A. C. Apoio matricial e equipe de referência: uma metodologia para gestão de trabalho interdisciplinar. Cadernos de Saúde Pública, Rio de Janeiro, v. 23, n. 2, p. 399-407, 2007.

DIMENSTEIN, M. et al. Demanda em saúde mental em Unidades de Saúde da Família. Revista de Saúde Mental e Subjetividade da UNIPAC, Barbacena, v. 3, n. 5, p. 24-40, 2005.

GODOY, M. G. C.; BOSI, M. L. M. A alteridade no discurso da reforma psiquiátrica brasileira face à ética radical de Lévinas. Revista de Saúde Coletiva, Rio de Janeiro, v. 17, n. 2, p. 289-299, 2007.

GOFFMAN, E. Estigma: notas sobre a manipulação da identidade deteriorada. Rio de Janeiro: LTC, 1988.

JUCA, V. J. S.; NUNES, M. O.; BARRETO, S. G. Programa de saúde da família e saúde mental: impasses e desafios na construção da rede. Ciência \& Saúde Coletiva, Rio de Janeiro, v. 14, n. 1 p. 173-182, 2009.

MERHY, E. E. A rede básica como uma construção da saúde pública e seus dilemas. In: ONOCKO, R. (Org.). Agir em saúde: um desafio para o público. São Paulo: $\mathrm{Hu}$ citec, 2006. p. 197-228.

NUNES, M.; TORRENTE, M. Estigma e violências no trato com a loucura: narrativas de centros de atenção psicossocial, Bahia e Sergipe. Revista de Saúde Pública, São Paulo, v. 43, n. 1, p. 101-108, 2009. 
QUEIROZ, V. D. C. A saúde mental na atenção primária. Serviço Social \& Realidade, Franca, v. 19, n. 1, p. 125-152, 2010.

SILVA, C. S. A saúde mental na perspectiva da atenção primária à saúde. 2010. $54 \mathrm{f}$. Dissertação (Mestrado em
Epidemiologia) - Universidade Federal do Rio Grande do Sul, Porto Alegre, 2010.

SILVEIRA, P. S.; VIEIRA, A. L. S. Saúde mental e Atenção Primária à Saúde em saúde: análise de uma experiência no nível local. Ciência \& Saúde Coletiva, Rio de Janeiro, v. 14, n. 1, p. 139-148, 2009.

\section{Contribuição dos Autores}

Meyrielle Belotti - coleta de dados, concepção do texto, organização de fontes, redação do texto. Maria Cristina Campello Lavrador - concepção do texto e revisão. Todos os autores aprovaram a versão final do texto. 